\title{
The hyperlipoproteinaemias
}

\author{
D. L. LEVENE* \\ M.D., M.Sc., F.R.C.P.(C) \\ The Unit of Clinical Cardiology, Department of Medicine, Royal Postgraduate Medical School, \\ London, $W .12$
}

\begin{abstract}
Summary
Elevated plasma lipids have been associated with an increased risk of ischaemic heart disease. However, regimens which reduce plasma lipids may decrease the recurrence rate of myocardial infarction. Accurate diagnosis of patients with elevated lipids and their families may be important in both secondary and primary prevention of atherosclerosis.

Classification of hyperlipoproteinaemias, the methods of diagnosis and an approach to dietary and drug therapy are discussed.
\end{abstract}

\section{Introduction}

Lipoproteins are plasma constituents consisting of lipid and a protein moiety. The lipid components (cholesterol and triglycerides) are of major clinical interest and may be readily quantitated biochemically. Transport of these lipids is a major function of the lipoproteins. Variation in density, size and charge of these moieties exist; and it is the beta-lipoproteins (very low density) which have been associated with clinical atherosclerosis. Chylomicrons, the largest of the lipoproteins, and the richest in triglycerides from dietary sources, remain at the origin on paper electrophoresis. The very low density lipoproteins transport endogenous triglyceride from the liver and form the pre-beta band on the electrophoretic strip. Of somewhat greater density are the lipoproteins which form the beta band and are responsible for transport of the largest proportion of the plasma cholesterol. The lipoproteins with the greatest density migrate with the alpha globulins and form the alpha band.

Many years of animal experimentation have consistently shown a relationship between elevated plasma lipid levels and atherosclerosis. Diets rich in saturated fat and/or cholesterol result in these abnormal lipid levels. In humans, elevated plasma

* Research Fellow in Clinical Cardiology, Royal Postgraduate Medical School and Hammersmith Hospital, London. Supported by The Wellcome Trust, United Kingdom.

Present address: Division of Cardiology, Sunnybrook Hospital, Bayview Avenue, Toronto, Canada. cholesterol is clearly a risk factor, known to be associated with an increased incidence of ischaemic heart disease (Stamler et al., 1966; Kannel et al., 1961). Genetic and geographic factors as well as diet influence the plasma level of cholesterol. There is evidence that hypertriglyceridaemia also may fall into this category. There is no longer any doubt that dietary manipulation (Keys, Anderson \& Grande, 1965 ) or the administration of drugs (Strisower, 1963) may lower the levels of these lipids. From a therapeutic viewpoint then, the vital questions concern how the rate of development of atherosclerosis will be altered by these manoeuvres. Preliminary studies have been encouraging in this regard, In one study (Leren, 1966) the first recurrence rate for myocardial infarction was significantly reduced when a low cholesterol diet was instituted. It seems reasonable then to assume a fairly active approach in patients with elevated plasma lipids.

\section{Classification}

Abnormal plasma concentrations of cholesterol and triglyceride may be found in various combinations. To clarify these lipid patterns, a system of phenotyping was introduced in 1967 (Fredrickson, Levy \& Lees, 1967). Five major lipoprotein patterns were defined by paper electrophoresis, and have been quantitated by other methods. These patterns are designated types $\mathrm{I}$ to $\mathrm{V}$ and may be familial or sporadic. They may moreover exist alone (primary) or be secondary, as in the hypercholesterolaemia of myxoedema.

\section{Type I}

In this disorder, there is an inability to clear dietary fat and hence there is a striking increase in the chylomicron fraction. It is almost always familial. Most patients are young and demonstrate lipaemia retinalis, hepatosplenomegaly, eruptive xanthomata and bouts of abdominal pain associated with the ingestion of fat. A discrete layer of fat forms in the plasma if a sample is allowed to stand in the cold. 
Plasma cholesterol is elevated and triglyceride concentration may be very high. A heavy chylomicron band is seen in the paper electrophoretic strip. Carbohydrate tolerance is usually normal.

\section{Type II}

This syndrome, which is relatively common, is frequently associated with accelerated atherosclerosis and a family history of early death. The disorder is characterized by a marked increase in beta-lipoproteins. Plasma cholesterol level may be as high as $600 \mathrm{mg} / 100 \mathrm{ml}$ with normal or near normal triglycerides. The plasma in contrast to type $I$ is perfectly clear. A heavy beta-lipoprotein band is seen on paper electrophoresis. Carbohydrate tolerance is normal. Secondary causes of this syndrome such as hypothyroidism, nephrosis, liver disease and myeloma can be ruled out by the appropriate function and screening tests. Diagnosis of the familial form of this disorder requires the demonstration of the lipoprotein pattern in the patient and at least one close relative. Xanthomata and ischemic heart disease in childhood are strongly suggestive of the homozygous state. A heterozygote may demonstrate tendinous and tuberous xanthomata, xanthelasma and arcus senilis at a more advanced age.

\section{Type III}

This disorder is considered to occur only in the primary form. Male patients present in their third or fourth decade with tubero-eruptive xanthomata on their knees, elbows and buttocks and orange lipid deposits in the creases of the palms of the hands. Ischemic heart disease and peripheral vascular disease are common and frequently severe. The beta lipoproteins are heavily laden with triglyceride as well as cholesterol and hence both triglyceride and cholesterol in the plasma are markedly elevated. Fasting plasma may be clear, cloudy or milky. A broad beta band is seen on electrophoresis. Ultracentrifugation is required for precise diagnosis. Abnormal carbohydrate tolerance is said to exist in about $40 \%$ of these patients.

\section{Type IV}

This disorder is often familial but very rare in children. It occurs much more frequently in adults, and is associated with abnormal carbohydrate tolerance in $75 \%$ of patients. Both primary and secondary forms exist; the latter associated with diabetes mellitus, pancreatitis and hypothyroidism. Premature atherosclerosis may be the commonest presentation. Hepatosplenomegaly and cutaneous lipid deposits are less common. There is an increase in the pre-beta or very low density lipoproteins which is thought to reflect an imbalance in the metabolism of endogenous triglycerides. The increase of this lipid fraction is fre- quently but not always seen after the ingestion of carbohydrate. The plasma may be clear, cloudy or milky. Hyperuricaemia is also frequently present. Plasma triglycerides are always elevated and cholesterol may or may not be increased. Paper electrophoresis reveals a band in the pre-beta region.

\section{Type $V$}

This is a mixed pattern in which both chylomicrons and very low density (pre-beta) lipoproteins are elevated. These patients frequently have recurrent abdominal pain with or without evidence of pancreatitis, usually after the age of 20 . It may be familial (primary) or secondary to diabetic acidosis, alcoholism, pancreatitis or the nephrotic syndrome. Lipaemia retinalis, hepatosplenomegaly and eruptive xanthomata may be associated, as in type I. A normal carbohydrate tolerance and hyperuricaemia are frequently present, in contrast to type $I$.

Plasma cholesterol is increased and the triglyceride level is frequently very high. The plasma is therefore often creamy. Both a heavy chylomicron band and a pre-beta band are seen on paper electrophoresis.

\section{Diagnosis}

A detailed history and physical examination are essential and may provide a clue to a familial disorder or aid in the diagnosis of diseases causing the secondary form of this syndrome. Examination of the fasting plasma after overnight storage in the refrigerator is helpful. If a layer of fat is visible, types I or $\mathrm{V}$ are suggested. Turbid plasma is more suggestive of types III and IV. The plasma in type II is perfectly clear.

Plasma cholesterol and triglycerides should be measured in the fasting state. Marked elevation of triglyceride with little increase in cholesterol is suggestive of types I or V. Elevation of cholesterol with normal or slightly increased triglyceride in the presence of clear plasma is highly suggestive of type II disease. In the type III disorder, cholesterol and triglycerides are elevated to approximately the same extent.

Increase in triglycerides with normal or slightly increased cholesterol is seen in type IV disease.

Electrophoresis is required to determine the specific lipoprotein fraction that is increased.

\section{Management \\ General principles}

After underlying disorders have been excluded, various measures can be employed to lower lipid levels. This is desirable, since at least three of the types (II, III, IV) are associated with accelerated atherosclerosis. In severe hyperlipidaemias it is necessary to advocate vigorous treatment. When only moderate elevations of lipids are found, however, the decision to initiate treatment depends not only 
on the biochemical evidence, but also on age and the presence of other risk factors of ischemic heart disease. In younger patients, treatment is more urgent because of a greater tendency for early ischemic heart disease to be correlated with hyperlipidemia. Moreover, reduction in plasma cholesterol may be effective in the prophylaxis of recurrent infarction in young patients (Leren, 1966). Perhaps even those patients with lipid levels at the upper limits of normal should also be treated, as the incidence of ischemic heart disease increases with plasma cholesterol levels, even within the so-called normal range.

Diets, in general, are the safest and most effective long-range method of treating lipid disorders. Once initiated, diets can be continued for life, for if the patient becomes habituated to the diet, adherence becomes easy and routine. Dietary measures will be adequate for many, but not all patients. If adherence to the diet is impossible, or the diet fails to improve the disordered lipid pattern, drugs may be needed. Initially all patients should be placed on a suitable diet alone, which can be supplemented if necessary by drugs to obtain the maximum response.

Simple weight reduction may be effective in lowering serum lipids, especially triglycerides (Fredrickson et al., 1967; Antonis \& Bersohn, 1961). Thus patients should strive for the ideal body weight. Reduction of the total intake of fat and limitation of excessive amounts of refined carbohydrate are necessary.

Polyunsaturated fats if included in the diet will lower the plasma cholesterol (Antonis \& Bersohn, 1961). Saturated fats have the opposite effect. The elimination or restriction of meats containing fat, most dairy products (except skimmed milk and cottage cheese), egg yolks, chocolate and pastries and the substitution of fish, fowl, nuts, vegetable margarines and salad oils in reasonable quantities will produce the desired result. A diet high in protein $(25 \%$ of calories), moderate in carbohydrates $(40 \%)$ and moderate in total fat $(35 \%)$ of which polyunsaturated fats make up the greatest component has been recommended (Page \& Stamler, 1968). Probably the intake of refined sugars should also be restricted (Kuo, 1968).

\section{Treatment of specific disorders Type I}

A diet low in fat results in a dramatic clearing of the hyperchylomicronaemia and resolution of the abdominal complaints. No drugs are effective, but the diet may be made more palatable by substituting medium chain-length triglycerides, i.e. neutral fats with shorter side-chains which do not provoke the syndrome.

\section{Type II}

A low cholesterol diet (less than $300 \mathrm{mg} /$ day) and increased amounts of polyunsaturated fats will reduce plasma cholesterol by about $25 \%$. Cholestyramine resin in a dose of 12-32 g/day, an agent which binds bile salts in the gastrointestinal tract and thus increases plasma cholesterol utilization will add to the dietary effect on serum cholesterol. Clofibrate, an agent which reduces hepatic synthesis of lipoproteins, and is often effective in lowering plasma cholesterol and triglycerides if raised, may be tried, but often has little effect in this syndrome. Both nicotinic acid $(1-3 \mathrm{~g} /$ day) and d-thyroxine (4-8 $\mathrm{mg} /$ day) can be used. The latter, an analogue of thyroid hormone, has less metabolic effect than 1-thyroxine, but must be given in doses sufficiently large to cause unpleasant sideeffects resembling hyperthyroidism. The severe flushes that result from nicotinic acid are well known. Thus cholestyramine is probably the drug of choice, although it is unpleasant to take and steatorrhea, vitamin deficiencies and constipation may occur (see Table 1).

\section{Type III}

This type, usually very responsive to treatment, may respond to weight-reduction alone. With a low cholesterol reducing diet, or clofibrate $2 \mathrm{~g}$ daily, or a combination, one may expect normal levels of plasma cholesterol and triglycerides.

\section{Type IV}

Therapy for this disorder includes weight reduction and dietary restriction of carbohydrate to less than $33 \%$ of the calorie intake. Clofibrate may also be used, and if carbohydrate intolerance is present, a sulphonylurea, such as tolbutamide, should be the drug of choice.

\section{Type $V$}

The patients are sensitive to both fat and carbohydrate. Weight-reduction is the first step in management. The diet should have as high a protein content as possible with a balanced proportion of fats and carbohydrate. Clofibrate and hypoglycaemic agents may be tried if necessary, but may prove ineffective. Drug therapy can be summarized in Table 1 .

\section{Conclusions}

There is no doubt that the hyperlipidaemias increase the risk of ischaemic heart disease. Reduction of plasma lipids may improve the prognosis especially in young patients. Accurate diagnosis and a vigorous therapeutic approach in many patients are therefore justified. Management should include investigation of members of the families of patients, and consideration of therapy for those with abnormal lipid patterns. It is hoped that primary prevention will prove of great importance in such asymptomatic 
TABLe 1. Drugs

\begin{tabular}{|c|c|c|c|}
\hline Type & Therapy & Mechanism of action & Side-effects and disadvantages \\
\hline I. & $\begin{array}{l}\text { Low fat diet }(20 \% \text { of calorie } \\
\text { intake) }\end{array}$ & $\begin{array}{l}\text { Lack of exogenous chylomicrons to } \\
\text { provoke the syndrome. }\end{array}$ & Diet may be unpalatable. \\
\hline \multirow[t]{3}{*}{ II. } & $\begin{array}{l}\text { Low cholesterol diet (less than } \\
200 \mathrm{mg} / \text { day) } \\
\text { (A) Cholestyramine } 12-32 \\
\text { g/day }\end{array}$ & $\begin{array}{l}\text { Increases excretion of bile acids by bind- } \\
\text { ing in the gastro-intestinal tract and } \\
\text { hence causes drainage of cholesterol } \\
\text { pool used for bile acid production. }\end{array}$ & $\begin{array}{l}\text { Bulky unpleasant taste, odour, con- } \\
\text { stipation steatorrhea, deficiency of } \\
\text { fat soluble vitamins. }\end{array}$ \\
\hline & (B) Nicotinic acid $2-6 \mathrm{~g} /$ day & $\begin{array}{l}\text { Possibly causes decrease in hepatic syn- } \\
\text { thesis of beta-lipoproteins. }\end{array}$ & $\begin{array}{l}\text { Flushing, pruritus, gastro-intestinal } \\
\text { symptoms. Hyperglycaemia, hyper- } \\
\text { uricemia, hepatic dysfunction. }\end{array}$ \\
\hline & (C) D-thyroxine $4-8 \mathrm{mg} /$ day & $\begin{array}{l}\text { Probably promotes the formation of bile } \\
\text { acids from cholesterol. }\end{array}$ & $\begin{array}{l}\text { Nervousness, diarrhoea, weight loss, } \\
\text { aggravation of angina pectoris in } \\
\text { patients with ischaemic heart disease. }\end{array}$ \\
\hline III. & $\begin{array}{l}\text { Low calorie reducing diet } \\
\text { ( } 1000 \text { calories/day) } \\
\text { Low cholesterol diet } \\
\text { Clofibrate } 2 \mathrm{~g} / \text { day }\end{array}$ & $\begin{array}{l}\text { May inhibit hepatic synthesis of lipopro- } \\
\text { teins and cholesterol. May enhance } \\
\text { faecal excretion of neutral sterols. }\end{array}$ & $\begin{array}{l}\text { Gastro-intestinal symptoms, weight- } \\
\text { gain, skin rash, prolongation of } \\
\text { prothrombin time, if given concur- } \\
\text { rently with anticoagulants. }\end{array}$ \\
\hline IV & $\begin{array}{l}\text { Low calorie reducing diet, } \\
\text { ( } 1000 \text { calories/day). Restric- } \\
\text { tion of carbohydrate intake } \\
\text { (less than } 35 \% \text { of total } \\
\text { calorie intake) } \\
\text { (A) Clofibrate } \\
\text { (B) Tolbutamide } 1-2 \mathrm{~g} / \text { day }\end{array}$ & $\begin{array}{l}\text { Stimulation of insulin secretion and } \\
\text { hence improvement of carbohydrate } \\
\text { tolerance. }\end{array}$ & $\begin{array}{l}\text { Rarely hypoglycaemia, blood dys- } \\
\text { crasias, gastro-intestinal symptoms } \\
\text { skin rash. }\end{array}$ \\
\hline V & $\begin{array}{l}\text { Low calorie reducing diet } \\
(1000 \text { calories/day). High in } \\
\text { protein with balanced fat } \\
\text { and carbohydrate }\end{array}$ & - & - \\
\hline
\end{tabular}

people. Dietary measures are safe and frequently all that is needed. The possible contribution of smoking and hypertensive disease should not however be forgotten and if necessary appropriate measures taken. Drugs will add to the effect of diet on lipids and should be considered in many cases. Follow-up objective evidence of changes in the lipid pattern as therapy proceeds is essential.

\section{Acknowledgment}

To Professor J. F. Goodwin for his help in preparing the manuscript.

\section{References}

Antonis, A. \& Bersohn, I. (1961) The influence of diet on serum triglycerides. Lancet, i, 3.

Fredrickson, D.S., Levy, R.I. \& Lees, R.S. (1967) Fat transport in lipoproteins-an integrated approach to mechanisms and disorders New England Journal of Medicine, 276, 34, 94, 148, 215, 273.

Hegsted, D.M., McGandy, R.B., Myers, M.L. \& Stare, F.J. (1965) Quantitative effects of dietary fat on serum cholesterol in man. American Journal of Clinical Nutrition, 17, 281 .
Kannele, W.B., Dawber, T.R., Kagan, A., Revotski, N. \& StOKES, J. III (1961) Factors of risk in the development of coronary heart disease. Six year follow up experience. The Framingham Study. Annals of Internal Medicine, $55,33$.

Keys, A. Anderson, J.T. \& Grande, F. (1965). Serum cholesterol reponse to changes in the diet. 1. Iodine value of dietary fat versus $25-P$. II. The effect of cholesterol in the diet. III. Differences among individuals. IV. Particular saturated fatty acids in the diet. Metabolism, 14, 747.

Kuo, P.T. (1968) Current metabolic-genetic inter-relationships in human atherosclerosis. With therapeutic considerations. Annals of Internal Medicine, 68, 449.

LEREN, P. (1966) The effect of plasma cholesterol lowering diet in male survivors of myocardial infarction. A con-, trolled clinical trial. Acta Medica Scandinavica, Suppl. 466.

Page, I.H. \& Stamler, J. (1968) Diet and coronary heart disease. Modern Concepts of Cardiovascular Disease, 37, 119.

Stamler, J. Berkson, D.M., Lindberg, H.A., Hall, Y., Miller, W., Monjonnier, L., Levinson, M., Cohen, D.B. \& Young, Q.D. (1966) Coronary risk factors. Their impact and their therapy in the prevention of coronary heart disease. Medical Clinics of North America, 50, 229.

STRISOWER, E.H. (1963) The response of hyperlipoproteinemias to atromid and ethyl chlorophenoxyisobutyrate Journal of Atherosclerosis Research, 3, 445. 